\title{
Traumatic injury of radial and ulnar artery with perfusion of the hand through the median artery: a case report
}

\section{Lesión traumática de arteria radial y ulnar con perfusión de la mano a través de la arteria mediana: reporte de caso}

\author{
Daniela Calderón Ardila ${ }^{1}$ Daniel Raúl Ballesteros Larrota ${ }^{1}$ María Andrea Calderón Ardila $^{2}$ \\ (D) Luis Ernesto Ballesteros Acuña ${ }^{3}$ (D) \\ dani.ca_026@hotmail.com
}

1 Universidad Industrial de Santander, Facultad de Salud, Especialización Cirugía Plástica Estética y Reconstructiva. Bucaramanga, Colombia, 2 Universidad del Rosario, Escuela de Medicina, Ciencias de la Salud, Especialización en Radiología. Bogotá, Colombia., 3 Universidad Industrial de Santander, Facultad de Salud, Departamento de Ciencias Básicas. Bucaramanga, Colombia,

Citation: .Calderon AD, Ballesteros LDR, Calderon AMA, Ballesteros ALE Traumatic injury of radial and ulnar artery with perfusion of the hand through the median artery: a case report. Colomb Méd (Cali), 2021; 52(2):e5024521 http://doi. org/10.25100/cm.v52i2.4521

Received : 28 Aug 2020

Revised: $\quad 13$ Oct 2020

Accepted : 13 May 2021

Published: 25 May 2021

Keywords:

Anatomic variation, vascular system injuries, median artery, angiography, ulnar artery, radial artery, anastomosis, surgical

Palabras clave:

Lesiones del sistema vascular, variación anatómica, arteria mediana, angiografía por tomografía computarizada, informes de casos

Copyright: @ 2021 Universidad del Valle (c) (1) $\odot$

\section{Abstract}

\section{Case description:}

A young male patient with a complete section of the ulnar and radial arteries preserved the perfusion of the hand through an anatomical variant, the median artery, identified by angiotomography.

\section{Clinical Findings:}

A wound in the distal third of the left forearm with present pulses and adequate hand coloration. An angiotomography of the upper left limb showed a median artery originating as a continuation of the anterior interosseous artery and ending in the palm of the hand with an incomplete superficial palmar arch.

\section{Treatment and Outcomes:}

Ligation of both radial and ulnar arteries was performed. It was not possible to follow up the patient.

\section{Clinical Relevance:}

Forming the superficial and deep palmar arches, the irrigation of hand comes from the ulnar and radial arteries, which can compromise the viability of the limb when injured. The median artery is present in $0.6-21.1 \%$ of the population, originates from the anterior interosseous artery (branch of the ulnar), accompanies the median nerve in its path and ends in the palm joining the superficial palmar arch. Diagnostic imaging is a key tool for assessing arterial circulation and characterizing upper limb vascular lesions. Knowledge of the anatomical variations of the arterial supply of the hand, including variability of the superficial palmar arch, is crucial for the safety and success of hand surgeries. 


\section{Acknowledgments:}

We thank Dr. Luis Eduardo Franco Ospina for his contribution in the interpretation of the diagnostic images.

\section{Corresponding author:}

Daniela Calderón Ardila. Ruitoque Condominio Conjunto Buena Vista Cabaña 15, Piedecuesta, Santander, Colombia. Cel: 3118921563.e-mail: dani.ca_026@hotmail.com

\section{Resumen}

\section{Descripción del caso:}

Un paciente joven de sexo masculino con sección completa de las arterias cubital y radial conservó la perfusión de la mano a través de una variante anatómica, la arteria mediana, identificada por angiotomografía.

\section{Hallazgos clínicos:}

Herida en el tercio distal del antebrazo izquierdo con pulsos presentes y coloración adecuada de la mano. Una angiotomografía del miembro superior izquierdo mostró una arteria mediana que se originaba como continuación de la arteria interósea anterior y terminaba en la palma de la mano con un arco palmar superficial incompleto.

\section{Tratamiento y resultados:}

Se realizó la ligadura de las arterias radial y cubital. No fue posible realizar un seguimiento del paciente.

\section{Relevancia clínica:}

La irrigación de la mano proviene de las arterias cubital y radial, que forman los arcos palmar superficial y profundo, comprometiendo la viabilidad de la extremidad cuando se lesionan. La arteria mediana está presente en el 0.6-21.1\% de la población, se origina en la arteria interósea anterior (rama del cubital), acompaña al nervio mediano en su recorrido y termina en la palma uniéndose al arco palmar superficial. El diagnóstico por imagen es una herramienta clave para evaluar la circulación arterial y caracterizar las lesiones vasculares del miembro superior. El conocimiento de las variaciones anatómicas de la irrigación arterial de la mano, incluida la variabilidad del arco palmar superficial, es de importancia crucial para la seguridad y el éxito de las cirugías de la mano.

\section{Introduction}

The irrigation of the upper limb comes from the brachial artery, which bifurcates at the elbow into the radial and ulnar arteries. The interosseous trunk arises from the ulnar artery and bifurcates into an anterior and a posterior branch. The hand perfusion is established from the superficial and deep palmar arches, which receive contributions from the radial and ulnar arteries.

The median artery is an embryological remnant considered an anatomical variation. It can arise from the ulnar artery, the common interosseous artery, or the anterior interosseous artery, ending in the superficial palmar arch in different patterns. No case has been reported in the literature with vascular trauma in the forearm associated with perfusion of the hand through the median artery, which makes this case unique.

\section{Case description}

A 33-year-old male patient with a medical history of drug abuse and numerous surgical interventions in the chest and abdomen due to trauma presented to the hospital's emergency room with multiple knife wounds in the chest and extremities one hour after the assault. He had no previous injuries to his upper limbs. The patient was brought immediately to the operating room after being admitted for a thoracostomy to treat pneumothorax. During the procedure, a wound in the distal third of the left forearm was explored (Figure 1), observing section of 
the flexor digitorum superficialis tendon, section of the ulnar nerve and section of the radial and ulnar arteries. The management of these lesions was deferred owing to the hemodynamic instability of the patient.

The patient improved his general condition and was followed daily by the plastic surgery service. It was not necessary to intervene on vascular lesions due to the adequate perfusion of the hand. A second surgery was performed by the plastic surgeons five days later. However, due to strong pulses and adequate coloration of the hand and taking into account that the window for arteriorrhaphy was over, ligation of both radial and ulnar arteries was performed. Interventional radiology was not available at the time for angiography. Therefore, an upper left limb angiotomography was requested for further evaluation.

The imaging study showed a median artery originating as a continuation of the anterior interosseous artery (Figure 2) and ending in the palm with an incomplete superficial palmar arch (Figure 3). It was inferred that the preserved perfusion of the hand (Figure 4) without the need for anastomosis of the ulnar or the radial artery was secondary to the presence of the anatomical variant diagnosed in the scan (Figure 5). There was no adverse reaction to the contrast.

Because of the social condition of the patient and no introspection about his clinical condition, there was no adherence to treatment, and he did not attend follow-up controls. The prognosis and outcome are poor due to tendon and nerve injuries. Additionally, he may present transient ischemia of the hand and compression syndrome of the median nerve due to hypertrophy of the median artery.

The written informed consent was obtained from the patient for the publication of this case report.

\section{Discussion}

The brachial artery at the elbow bifurcates into the radial and ulnar arteries. The interosseous trunk arises from the ulnar artery and divides into an anterior and a posterior branch. The ulnar and radial arteries continue through the forearm to the hand and then establish the superficial and deep palmar arches ${ }^{1}$.

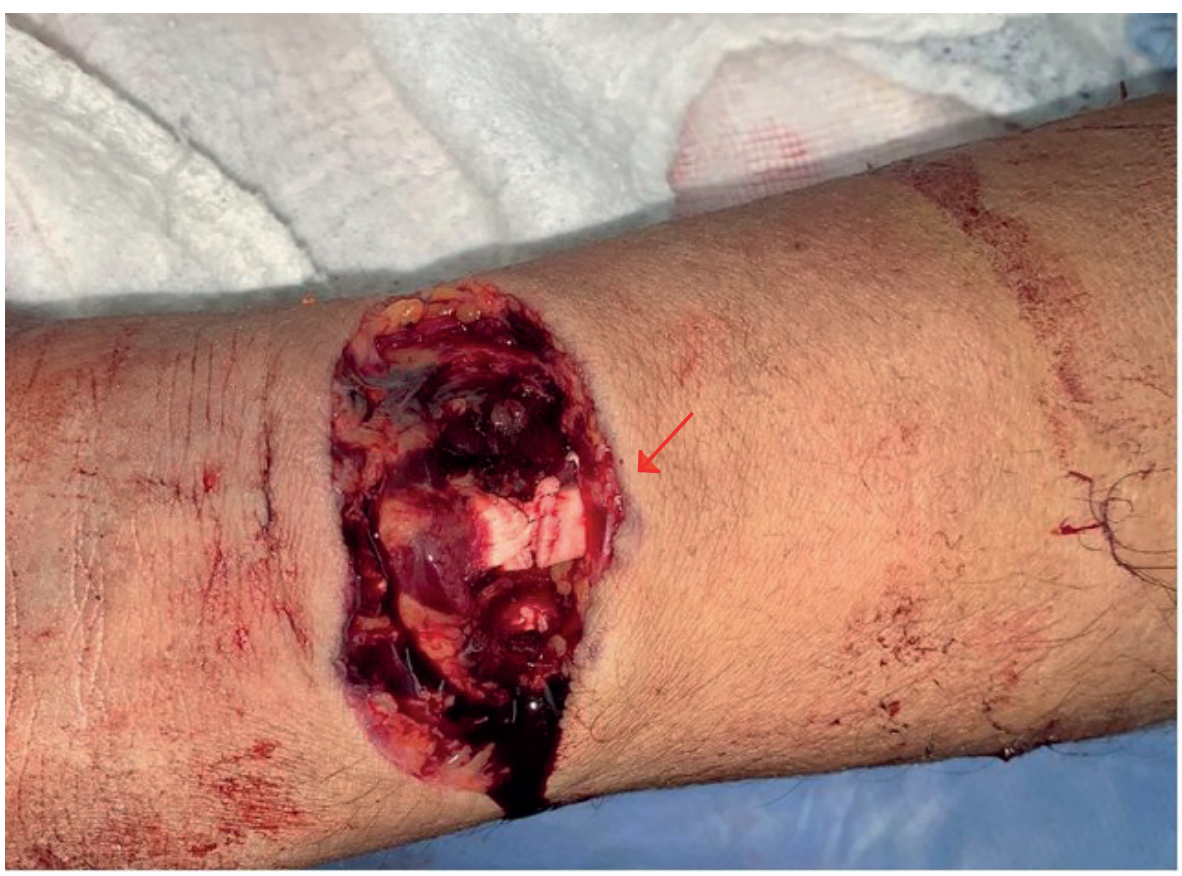

Figure 1: 33-year-old male. Wound in the distal third of the left forearm (red arrow) with a complete section of radial and ulnar arteries. 


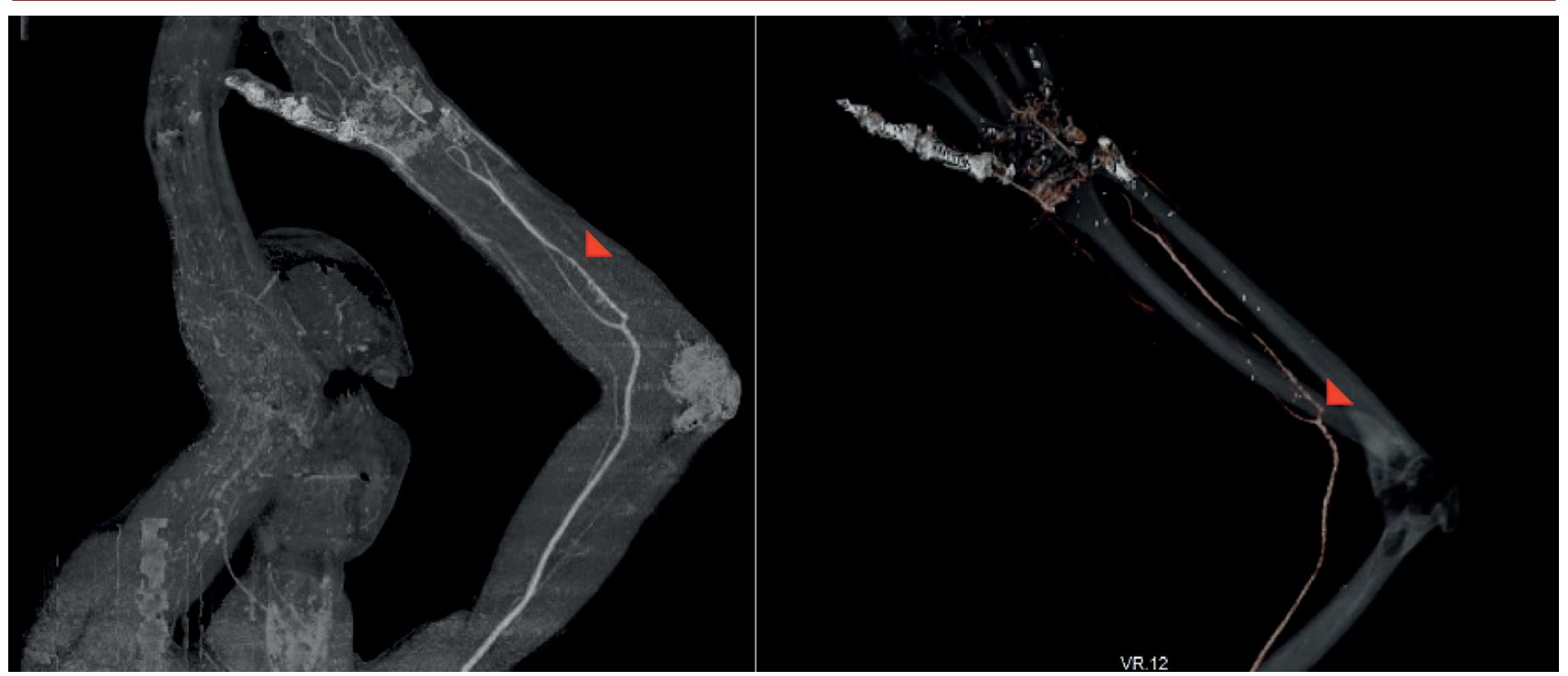

Figure 2. 33-year-old male. A complete section of radial and ulnar arteries. A. The red arrow indicates the median artery. B. The red arrow indicates the origin of the median artery as a continuation of the anterior interosseous artery. Angiotomography. Ioversol injection. $100 \mathrm{~mL}$. 3 seconds.

There are numerous clinically important anatomical variations of the arterial pattern within the upper limb, which might refer to an atypical number, origin or course of the arteries ${ }^{2}$. The persistent median artery (PMA) is an embryological remnant considered an anatomical variation. During the first weeks of intrauterine development, the median and anterior interosseous arteries are the main sources of blood supply to the hand. After the eighth week of gestation, radial and ulnar arteries develop, and the median artery atrophies. However, in some individuals, this artery persists throughout life ${ }^{3,4}$.

In anatomical studies, the PMA has been reported in a range between $0.6 \%$ to $21.1 \%$ of individuals. It could arise from the ulnar artery, the common interosseous artery, or the anterior interosseous artery ${ }^{2,5}$. The PMA can be presented in an antebrachial pattern, in which the artery provides blood supply to the median nerve but does not reach the hand, and a palmar pattern in which it passes through the carpal tunnel to connect itself to the superficial palmar arch ${ }^{34,6,7}$.

Penetrating trauma by knife, glass or machinery is an important cause of injuries to the radial and/or ulnar artery in the forearm and wrist ${ }^{8}$. Computed tomography angiography (CTA) is a radiographic-based modality that reproduces the arterial vasculature through 3-D volumetric analysis. CTA can rapidly diagnose a vascular injury and is useful in determining the location, nature, and extent when it is not evident on physical examination ${ }^{8}$.

In the presence of hard signs of vascular injury, patients are urgently brought to the operating room. However, forearm arterial repairs in a well-perfused hand have shown no difference in functional outcome when taken to the operating room within 6 hours or in a delayed manner. In the setting of single-artery damage (either radial or ulnar) with intact perfusion of the hand, ligation versus repair is a topic of debate ${ }^{8}$.

Ischemia of the hand typically occurs in the setting of an injury to both the radial and ulnar arteries ${ }^{8}$. In the case presented, the radial and ulnar pulses were not palpable. However, the patient had perfusion of the hand evidenced by adequate coloration, absence of coldness and capillary filling of two seconds. For that reason, a CTA was requested to evaluate the vascular lesion since the findings on physical examination were not consistent.

According to Eid, et al. classification, the patient had an incomplete superficial arch (Figure 4), type D pattern, in which the PMA does not anastomose with the radial or ulnar arteries. The 


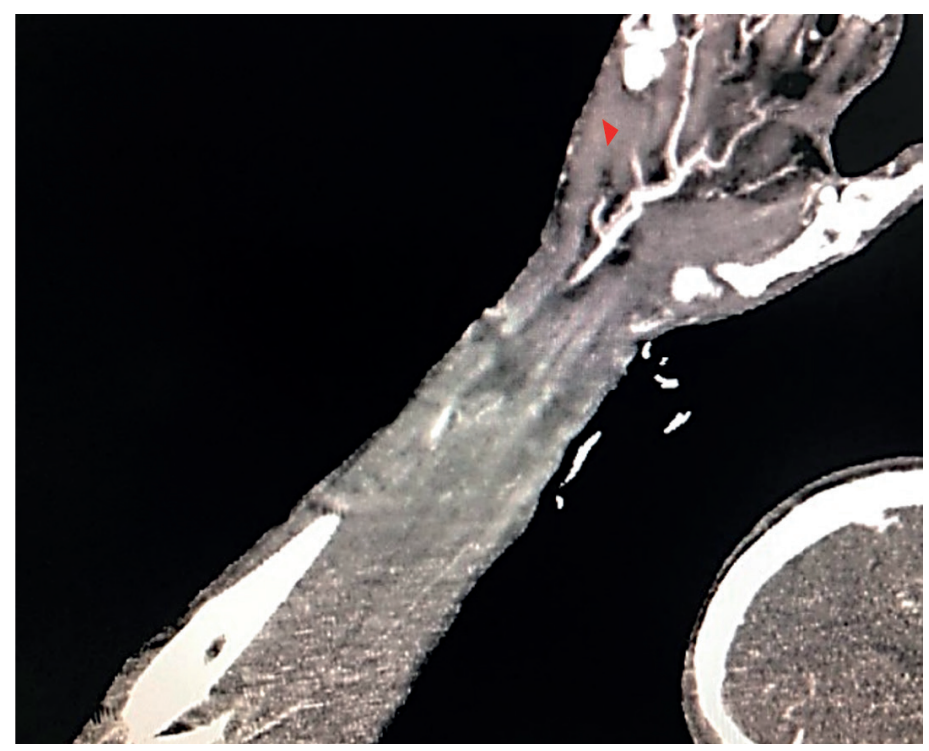

Figure 3. 33-year-old male. A complete section of radial and ulnar arteries. The red arrow indicates the incomplete superficial palmar arch by the median artery. Angiotomography. Ioversol injection. $100 \mathrm{~mL} .3$ seconds.

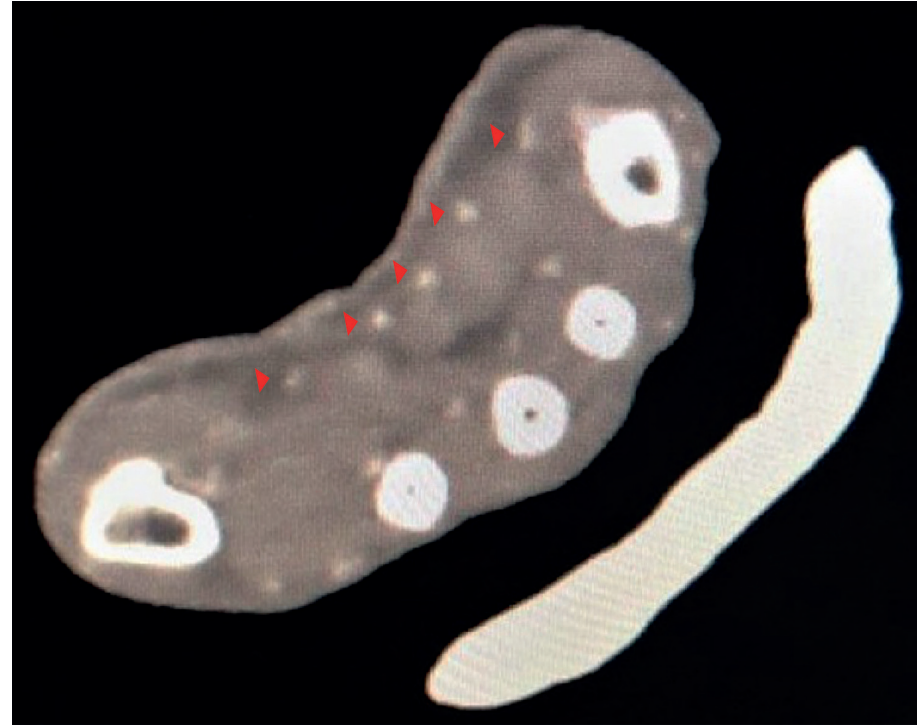

Figure 4. 33-year-old male. A complete section of radial and ulnar arteries. Red arrows are indicating the adequate perfusion of the hand. Angiotomography. Ioversol injection. $100 \mathrm{~mL} .3$ seconds.

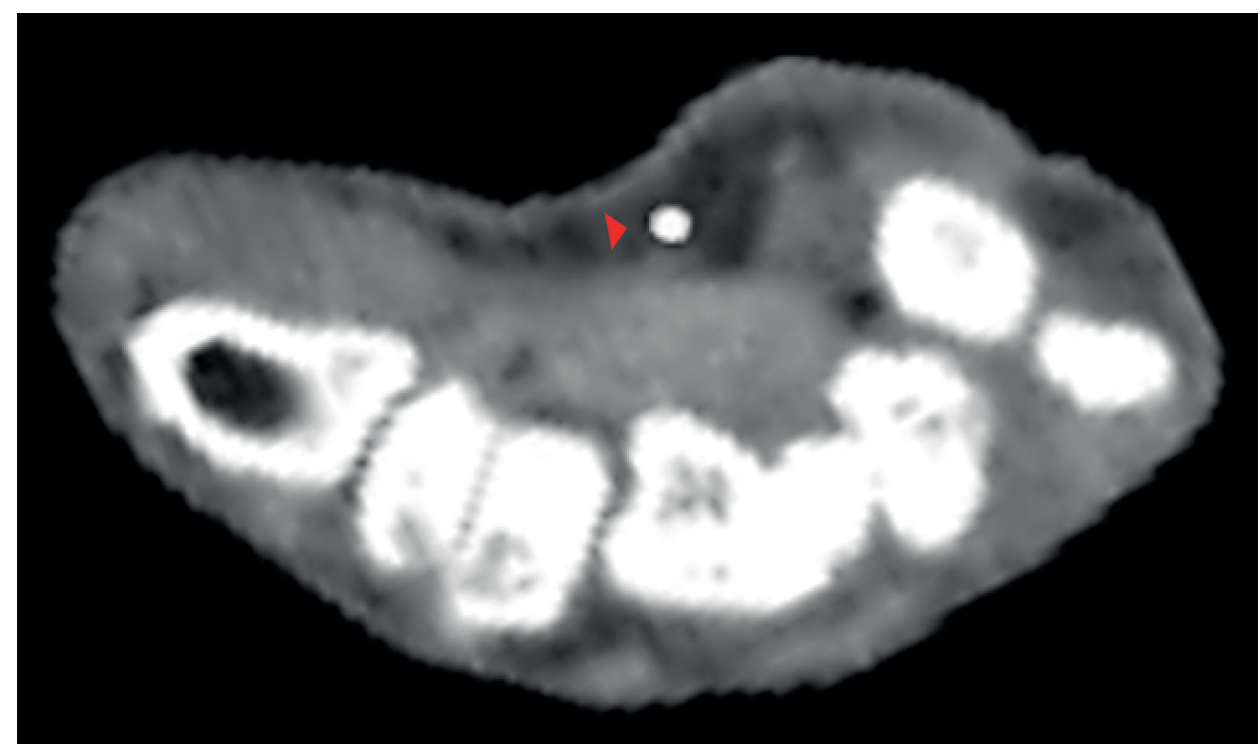

Figure 5. 33-year-old male. A complete section of radial and ulnar arteries. The red arrow indicates the median artery at the carpal level. The diameter of the persistent median artery at this level was $2.5 \mathrm{~mm}$. Angiotomography. Ioversol injection. $100 \mathrm{~mL} .3$ seconds

PMA has been reported in a diameter ranging from 0.8 to $2.7 \mathrm{~mm}^{9}$. The diameter of the PMA in the present report was $2.5 \mathrm{~mm}$, which is in a high range compared to the literature. This finding could be explained that the radial and ulnar arteries were injured, and thus the PMA was dilated to be able to assume the perfusion of the hand.

The PMA has clinical implications related to compression of the median nerve and anterior interosseous nerve in the proximal forearm. This results in pronator syndrome and anterior interosseous nerve syndrome ${ }^{3,4,10-14}$. However, the existence of a median artery could be beneficial to patients with trauma in the forearm that compromises the radial and ulnar arteries. In this case, the unscathed median artery assured the perfusion of the hand despite the double vascular injury. 
A strength of this case report is the correlation of the clinical and radiological findings that allowed us to understand why the hand still perfused despite the injuries of the radial and ulnar arteries. Moreover, there are no reports in the literature that present a case with vascular trauma of the forearm in the presence of perfusion of the hand through the PMA, which makes this case unique.

The limitations of this case are the absence of arteriorrhaphy due to the clinical context of the patient, who was admitted hemodynamically unstable. At that moment, priority was given to his vital injuries in the chest. The vascular repair was not performed in the following days at the hospital, this being an unsafe decision due to the risk of ischemia. Likewise, we do not have outpatient follow-up because he did not attend the controls due to his poor adherence and introspection.

\section{Conclusion}

Proper knowledge of anatomic variations is mandatory for a hand surgeon. The PMA is a frequent anatomic variation and the compression syndromes secondary are very well known. However, the presence of the PMA could be beneficial in a vascular trauma context at the forearm level. The clinical findings must rely on diagnostic imaging to understand those not easy to explain, which provides relevant information for the surgeons.

\section{References}

1. Drake R, Vogl A. W., Mitchell A. Gray's Anatomy for Students. Elsevier Health Science. Fourth edition. 2019.

2. Haladaj R, Wysiadecki G, Dudkiewicz Z, Polguj M, Topol M. Persistent median artery as an unusual finding in the carpal tunnel: its contribution to the blood supply of the hand and clinical significance. Med Sci Monit. 2019; 25: 32-39. doi: 10.12659/MSM.912269.

3. Nayak S.R., Krishnamurthy A, Madhan Kumar SJ, Prabhu L.V., Potu B.K., D'Costa S., et al. Palmar type of median artery as a source of superficial palmar arch: a cadaveric study with its clinical significance. Hand (N Y). 2010; 5(1): 31-36. doi: 10.1007/s11552-009-9197-4.

4. Singla R.K., Kaur N, Dhiraj G.S. Prevalence of the persistant median artery. J Clin Diagn Res. 2012; 6(9): 1454-1457. doi: 10.7860/JCDR/2012/4218.2531.

5. Rodríguez-Niedenführ M., Sañudo J.R., Vásquez T., Nearn L., Logan B., Parkin I.. Median artery revisited. J Anat. 1999; 195(Pt 1): 57-63. doi: 10.1046/j.1469-7580.1999.19510057.x.

6. Coleman S S, Anson B J. Arterial patterns in the hand based upon a study of 650 specimens. Surg Gynecol Obstet. 1961;113:409-24.

7. Loukas M, Holdman D, Holdman S. Anatomical variations of the superficial and deep palmar arches. Folia Morphol (Warsz). 2005; 64(2):78-83.

8. Lebowitz C, Matzon J.L. Arterial injury in the upper extremity: evaluation, strategies, and anticoagulation management. Hand Clin. 2018; 34(1): 85-95. doi: 10.1016/j.hcl.2017.09.009.

9. Horst C, Schmitt O, Wree A. Large patent median arteries and their relation to the superficial palmar arch with respect to history, size consideration and clinic consequences. Surg Radiol Anat. 2008; 30(1):57-63. doi: 10.1007/s00276-007-0290-5.

10. Proudman T W, Menz P J. An anomaly of the median artery associated with the anterior interosseous nerve syndrome. J Hand Surg Br. 1992; 17(5):507-9. doi: 10.1016/s0266-7681(05)80231-1. 
Traumatic injury of radial and ulnar artery with perfusion of the hand through the median artery: a case report.

11. Lee M.J., LaStayo P.C. Pronator syndrome and other nerve compressions that mimic carpal tunnel syndrome. J Orthop Sports Phys Ther. 2004; 34(10):601-9. doi: 10.2519/jospt.2004.34.10.601.

12. Jones N F, Ming N L. Persistent median artery as a cause of pronator syndrome. J Hand Surg Am. 1988; 13(5):728-32. doi: 10.1016/s0363-5023(88)80135-7.

13. Gainor B J, Jeffries J T. Pronator syndrome associated with a persistent median artery. A case report. J Bone Joint Surg Am. 1987; 69(2):303-4.

14. Eid N, Ito Y, Shibata M A, Otsuki Y. Persistent median artery: cadaveric study and review of the literature. Clin Anat. 2011; 24(5): 627-33. doi: 10.1002/ca.211. 